\title{
Pure transvaginal umbilical hernia repair
}

\author{
Stephanie G. Wood · Lucian Panait • \\ Robert L. Bell · Andrew J. Duffy · Kurt E. Roberts
}

Received: 12 April 2012/Accepted: 8 January 2013/Published online: 23 February 2013

(C) Springer Science+Business Media New York 2013

\begin{abstract}
Background Transvaginal natural orifice transluminal endoscopic surgery (NOTES) procedures are at the forefront of minimally invasive innovation, remarkable for shorter recovery times and decreased postoperative pain [1, 2]. Most transvaginal procedures are performed as hybrid procedures [3]. To our knowledge, this is the first video depiction of a pure transvaginal umbilical hernia repair in a human.

Methods This is a 38-year-old woman, body mass index $36.4 \mathrm{~kg} / \mathrm{m}^{2}$, with a symptomatic port site hernia in the umbilical region after a previous laparoscopic cholecystectomy. The patient was positioned in stirrups in a steep Trendelenburg position. Sterilization of vaginal cavity was performed with $10 \%$ povidone-iodine solution. A $2 \mathrm{~cm}$ transverse incision at the posterior fornix was made, and a SILS port (Covidien, North Haven, CT) was introduced. One
\end{abstract}

Electronic supplementary material The online version of this article (doi:10.1007/s00464-013-2847-1) contains supplementary material, which is available to authorized users.

S. G. Wood - R. L. Bell · A. J. Duffy · K. E. Roberts $(\square)$

Department of Surgery, Yale School of Medicine, 40 Temple St., Suite 7B, New Haven, CT 06510, USA

e-mail: kurt.roberts@yale.edu

S. G. Wood

e-mail: stephanie.wood@yale.edu

R. L. Bell

e-mail: robert.bell@yale.edu

A. J. Duffy

e-mail: andrew.duffy@yale.edu

\section{Panait}

Drexel Bariatric Surgery at the Center for Surgical, Weight-Loss at Hahnemann University Hospital, 231 N. Broad Street, 3rd floor, Philadelphia, PA 19107, USA

e-mail: Lucian.Panait@drexelmed.edu
$12 \mathrm{~mm}$ trocar and two $5 \mathrm{~mm}$ trocars were placed through SILS port. Standard straight laparoscopic instruments were used. A $12 \mathrm{~cm}$ round Parietex mesh (Covidien) was placed in a specimen retrieval bag and deployed into the peritoneal cavity. The mesh was extracted, unfolded in the abdominal cavity, and circumferentially fixated to the abdominal wall with an AbsorbaTack device (Covidien). The colpotomy incision was closed with a running absorbable suture.

Results The procedure lasted $103 \mathrm{~min}$ and was performed on an outpatient basis. No intraoperative complications occurred. The patient was doing well and had no pain or recurrence at 2, 6, and 9 months' follow-up.

Conclusions Our initial experience with transvaginal ventral hernia repair in humans suggests that this procedure is feasible and safe. This approach may improve cosmesis and decrease the risk of future ventral hernias. Potential cons may include a longer operative time, mesh infection, and risk of visceral injury with a pure transvaginal approach. As transvaginal surgery evolves, techniques and devices will become increasingly refined to tackle these challenges.

Keywords Hernia - Human - NOTES .

Pure transvaginal $\cdot$ SILS $\cdot$ Transvaginal

\section{References}

1. Roberts KE, Solomon D, Mirensky T, Silasi DA, Duffy AJ, Rutherford T, Longo WE, Bell RL (2012) Pure transvaginal appendectomy versus traditional laparoscopic appendectomy for acute appendicitis: a prospective cohort study. Ann Surg 255:266-269

2. McGee MF, Rosen MJ, Marks J, Onders RP, Chak A, Faulx A, Chen VK, Ponsky J (2006) A primer on natural orifice transluminal endoscopic surgery: building a new paradigm. Surg Innov 13:86-93

3. Auyang ED, Santos BF, Enter DH, Hungness ES, Soper NJ (2011) Natural orifice translumenal endoscopic surgery (NOTES $\left.\left({ }^{\circledR}\right)\right)$ : a technical review. Surg Endosc 25:3135-3148 